\title{
Bacterial Wilt Resistance in Tomato, Pepper, and Eggplant: Genetic Resources Respond to Diverse Strains in the Ralstonia solanacearum Species Complex
}

\author{
A. Lebeau, M.-C. Daunay, A. Frary, A. Palloix, J.-F. Wang, J. Dintinger, F. Chiroleu, E. Wicker, and P. Prior
}

First, sixth, seventh, and eighth authors: CIRAD, UMR Peuplements Végétaux et Bioagresseurs en Milieu Tropicale (PVBMT), 7 Chemin de l'IRAT, 97410, Saint-Pierre Cedex, La Réunion; second and fourth authors: Institut National de la Recherche Agronomique (INRA), Centre d'Avignon, UR 1052, Unité de Génétique et Amélioration des Fruits et Légumes, Domaine St. Maurice, BP 94,84143 Montfavet Cedex, France; third author: Department of Molecular Biology and Genetics, Izmir Institute of Technology, Urla, Izmir, 35430, Turkey; fifth author: Asian Vegetable Research Development Center-The World Vegetable Center, P.O. Box 42, Shanhua, Tainan, Taiwan 741, R.O.C.; and ninth author: INRA/CIRAD, UMR PVBMT, 7 Chemin de l'IRAT, 97410, Saint-Pierre Cedex, La Réunion.

Accepted for publication 24 August 2010.

\begin{abstract}
Lebeau, A., Daunay, M.-C., Frary, A., Palloix, A., Wang, J.-F., Dintinger, J., Chiroleu, F., Wicker, E., and Prior, P. 2011. Bacterial wilt resistance in tomato, pepper, and eggplant: Genetic resources respond to diverse strains in the Ralstonia solanacearum species complex. Phytopathology 101:154-165.

Bacterial wilt, caused by strains belonging to the Ralstonia solanacearum species complex, inflicts severe economic losses in many crops worldwide. Host resistance remains the most effective control strategy against this disease. However, wilt resistance is often overcome due to the considerable variation among pathogen strains. To help breeders circumvent this problem, we assembled a worldwide collection of 30 accessions of tomato, eggplant and pepper (Core-TEP), most of which are commonly used as sources of resistance to $R$. solanacearum or for mapping quanti-

tative trait loci. The Core-TEP lines were challenged with a core collection of 12 pathogen strains (Core-Rs2) representing the phylogenetic diversity of $R$. solanacearum. We observed six interaction phenotypes, from highly susceptible to highly resistant. Intermediate phenotypes resulted from the plants' ability to tolerate latent infections (i.e., bacterial colonization of vascular elements with limited or no wilting). The CoreRs2 strains partitioned into three pathotypes on pepper accessions, five on tomato, and six on eggplant. A "pathoprofile" concept was developed to characterize the strain clusters, which displayed six virulence patterns on the whole set of Core-TEP host accessions. Neither pathotypes nor pathoprofiles were phylotype specific. Pathoprofiles with high aggressiveness were mainly found in strains from phylotypes I, IIB, and III. One pathoprofile included a strain that overcame almost all resistance sources.
\end{abstract}

Ralstonia solanacearum, the causal agent of bacterial wilt disease, ranks among the most devastating pathogens in solanaceous crops. The bacterium penetrates through the root system and proliferates in xylem tissue. Irreversible wilting generally develops quickly, resulting in plant death. This soilborne and vascular disease has a broad and expanding host range of $>200$ monocot and dicot plant species (42). The disease has spread worldwide because of the bacterium's capacity to adapt to tropical, subtropical, and temperate regions $(17,21$, $34,35)$. The lifestyle of $R$. solanacearum allows it to maintain, rapidly disseminate, or adapt to different ecological niches such as soil, water, and plant (nonhost rhizosphere and host xylem). The outstanding multifaceted characteristics of this xylem-invader mirror its extraordinary genetic and phenotypic diversity and dramatically increase the difficulties for its sustainable control.

Historically, classification of $R$. solanacearum strains has been partitioned into five races based on host range $(7,36,56)$ and six biovars based on trophic traits (33). More recently, phylogenetic analysis based on different molecular methods clearly showed that $R$. solanacearum encompasses a highly heterogeneous group of bacteria probably belonging to several species $(9,10,22,58,59)$

Corresponding author: P. Prior; E-mail address: philippe.prior@cirad.fr

* The $\boldsymbol{e}$-Xtra logo stands for "electronic extra" and indicates that the online version contains two supplemental figures and one supplemental table.

doi:10.1094/PHYTO-02-10-0048

(C) 2011 The American Phytopathological Society that cannot be taxonomically resolved by the race/biovar system. These molecular tools unraveled four distinctive phylotypes related to the geographical origin of the strains $(9,10,22)$ : phylotype I originated mainly from Asia, phylotype II from America, phylotype III from Africa, and phylotype IV from Indonesia. In addition to Indonesian strains of $R$. solanacearum, phylotype IV hosted the closely related species $R$. syzygii (Sumatra disease of clove) and the banana blood disease bacterium (BDB). Thus, the concept of species complex applies to the extreme phenotypic, genetic, and ecological variability among $R$. solanacearum isolates $(22,24)$. For this reason, we considered phylotype classification as the most appropriate basis for assigning a phylogenetic position to any particular strain or group of strains in this study.

For decades and in several countries, breeders of solanaceous crops have identified and used intra- or interspecific sources of resistance for creating bacterial wilt resistant cultivars of tomato, eggplant, and pepper (TEP) (2,3,14,27,31,45,50,51,62,67, $69,74,75)$. However, significant interactions of cultivar-location highlighted the importance of both site environmental conditions and pathogen population variability for the three species $(3,32$, $39,50-52,57,74)$. Cases of resistance breakdown under intensive culture have also been observed $(2,3)$. Hence, breeders face the challenging problem of variable efficiency of resistance expression, which is aggravated by an increasingly worldwide trade of TEP resistant cultivars. Instability of resistance in TEP is due to (i) insufficient knowledge of the mechanisms characterizing the resistant sources such as latent or absent infection, (ii) insufficient knowledge of the genetic characteristics of the strains used in TEP 
breeding programs, and, last but not least, (iii) strong but poorly known interactions between the genetic factors involved in host resistance and bacteria pathogenicity. Abiotic factors such as temperature, humidity, and nitrogen supply, as well as biotic factors such as plant co-infection by root-knot nematodes, also have an influence, often poorly controlled, over resistance expression, bacterium pathogenicity, and their interaction $(6,16$, $34,43)$. The genetic and phenotypic plasticity of $R$. solanacearum strains strongly hinders the use of varietal resistance as an efficient and sustainable control strategy.

The resistance of tomato (reference accession Hawaii 7996) is controlled by several mapped quantitative train loci (QTLs) with major or minor and broad-spectrum or strain-specific effects $(5,8,56,70,71,76)$. For eggplant, different patterns of genetic control have been described $(14,74)$ whereas, for pepper, the expression of resistance is quantitative (45). Depending on the resistance genitors and testing conditions used, field resistance in Solanaceae spp. is commonly assessed as a percentage of surviving plants, and is variable but rarely complete (i.e., 100\% surviving plants). Evaluation of resistance would benefit from examination of not only plant wilting but also bacterial colonization in unwilted plants. Indeed, the use of such detailed phenotypic characterization revealed that resistance can be either an ability to adapt to a latent bacterial colonization of the vessels (a tolerant phenotype) or, conversely, an ability to contain the bacteria in the lower parts of the vegetation (a resistant phenotype) (26).

Partitioning the genetic diversity of the $R$. solanacearum species complex in different phylotypes offered a new opportunity to reevaluate the resistance of solanaceous crops, challenged with phylogenetically diverse strains. The aim of this study was to characterize the interactions between resistant material and the agent of bacterial wilt. A core collection of TEP genotypes (CoreTEP), representative of the worldwide genetic diversity of the resistances available or used in reference mapping studies, was assembled. Similarly, a core collection of strains (Core-Rs), representative of the major phylogenetic diversity recognized within the $R$. solanacearum complex, was defined. We also included virulent variants (77) as well as representatives of the largely unstudied phylotype III African strains (53). Core-TEP was challenged by Core-Rs to examine their interactions. In this study, we considered pathogenicity to be an ability to cause the disease and virulence (synonymous aggressiveness) to be a degree or measure of the pathogenicity; in other words, a relative capacity to cause the disease.

\section{MATERIALS AND METHODS}

Bacterial strains. The main characteristics of $R$. solanacearum strains used in this study are shown in Table 1. At first, a set of 34 strains was assembled as a working collection (encoded CoreRs1) that encompassed the phylogenetic diversity of strains, some of which are known to be pathogenic in members of the family Solanaceae. These strains were chosen, out of thousands maintained in different collections, on the basis of their (i) host identity at the time of isolation and (ii) geographical origin. As a priority, we selected strains whose complete genomes have been sequenced and annotated: GMI1000 (66), IPO1609 (28), CMR15, PSI07, and CFBP2957 (64), as well as reference strains used in breeding programs and QTL mapping studies (PSS4 and JT516).

TABLE 1. Characteristics of Ralstonia solanacearum strains assembled as working collection encoded Core-Rs1

\begin{tabular}{|c|c|c|c|c|c|c|}
\hline Strain $^{\mathrm{a}}$ & Alternative name ${ }^{\mathrm{a}}$ & Host & Origin & Phylotype & GenBank $^{b}$ & Reference \\
\hline GMI1000 & RUN54, JS753 & Solanum lycopersicum & French Guyana & $\mathrm{I}-18$ & AF295251 & 58,61 \\
\hline CIP365 & RUN47, WP144 & S. tuberosum & Philippine & $\mathrm{I}-45$ & GQ907151 & 61 \\
\hline CMR134 & RUN215, CFBP7058 & Vaccinium membranaceum & Cameroon & $\mathrm{I}-13$ & EF439740 & 53 \\
\hline R288 & RUN90, UW373 & Morus alba & China & $\mathrm{I}-12$ & GQ907153 & 22 \\
\hline PSS190 & RUN85 & S. lycopersicum & Taiwan & $\mathrm{I}-15$ & EU407285 & This study \\
\hline MAFF211266 & RUN69, JT690 & S. lycopersicum & Japan & $\mathrm{I}-15$ & AF295250 & 58,61 \\
\hline PSS366 & RUN155 & S. lycopersicum & Taiwan & $\mathrm{I}-15$ & EU407299 & This study \\
\hline PSS216 & RUN156 & S. lycopersicum & Taiwan & $\mathrm{I}-13$ & EU407291 & This study \\
\hline PSS4 & RUN157, CIP410 & S. lycopersicum & Taiwan & $\mathrm{I}-15$ & EU407264 & This study \\
\hline UW151 & RUN158, ACH92 & Zingiber officinale & Australia & I-18 & AF295254 & 58,61 \\
\hline PSS358 & RUN159 & S. lycopersicum & Taiwan & $\mathrm{I}-15$ & EU407298 & This study \\
\hline IPO1609 & RUN1 & S. tuberosum & Netherlands & IIB-1 & EF371814 & 77 \\
\hline JT516 & RUN160 & S. tuberosum & Reunion & IIB-1 & AF295258 & 58,61 \\
\hline CMR34 & RUN147, CFBP7029 & S. lycopersicum & Cameroon & IIB-1 & EF439750 & 53 \\
\hline CIP10 & RUN40 & S. tuberosum & Peru & IIB-25 & AF295260 & 58,61 \\
\hline NCPPB3987 & RUN81, R590 & S. tuberosum & Brazil & IIB-28 & AF295261 & 58,61 \\
\hline CFBP6784 & RUN16, ANT307 & Anthurium andreanum & Martinique & IIB-4NPB & EF371813 & 22,77 \\
\hline CFBP6783 & RUN17, ANT75 & Heliconia caribea & Martinique & IIB-4NPB & EF371817 & 77 \\
\hline CIR02-080 & RUN18, ANT80 & A. andreanum & Martinique & IIB-4NPB & EF371819 & 77 \\
\hline ICMP7963 & RUN55, K197 & S. tuberosum & Kenya & IIA-7 & AF295263 & 58,61 \\
\hline CFBP2957 & RUN36, MT5 & S. lycopersicum & Martinique & IIA-36 & AF295265 & 22,58 \\
\hline CIP120 & RUN42, R563 & S. tuberosum & Peru & IIA-38 & GQ907152 & 61 \\
\hline CIP239 & RUN43, UW469 & S. tuberosum & Brazil & IIA-40 & AF295269 & 22,58 \\
\hline CMR39 & RUN150, CFBP7032 & S. lycopersicum & Cameroon & IIA-41 & EF439726 & 53 \\
\hline A3909 & RUN9 & H. rostrata & Hawaii & IIA-6 & EF371812 & 22,77 \\
\hline B34 & RUN22 & Musa sp. & Brazil & IIA-24 & GQ907154 & This study \\
\hline JT525 & RUN60 & Pelargonium asperum & Reunion & III-19 & AF295272 & 58,61 \\
\hline $\mathrm{J} 25$ & RUN56 & S. tuberosum & Kenya & III-20 & AF295279 & 22,58 \\
\hline CFBP3059 & RUN39, JS904 & S. melongena & Burkina Faso & III-23 & AF295270 & 22,58 \\
\hline CMR15 & RUN133, CFBP6941 & S. lycopersicum & Cameroon & III-29 & EF439743 & 53 \\
\hline CMR32 & RUN145, CFBP6942 & V. membranaceum & Cameroon & III-29 & EF439749 & 53 \\
\hline PSI07 & RUN83 & S. lycopersicum & Indonesia & IV-10 & EF371804 & 22,77 \\
\hline MAFF301558 & RUN71, JS934 & S. tuberosum & Japan & IV-8 & DQ011558 & 22,23 \\
\hline $\mathrm{ACH} 732$ & RUN14, UW433 & S. lycopersicum & Australia & IV -8 & GQ907150 & 22 \\
\hline
\end{tabular}

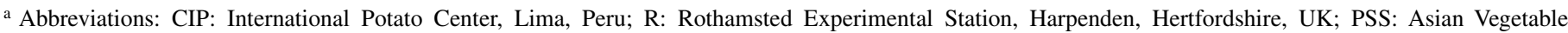

Research Development Center-The World Vegetable Center Collection, Shanhua, Taiwan; ACH: Hayward, Department of Microbiology, Centre for Bacterial Diversity and Identification, The University of Queensland, St Lucia, Australia; UW: University of Wisconsin-Madison, USA; CFBP: Collection Française de Bactéries Phytopathogènes, Angers, France; RUN: collection at CIRAD-INRA Reunion.

b GenBank accession numbers for partial endoglucanase gene $(e g l)$ sequence. 
Strains CFBP6784, CFBP6783, and CIR02-080 were representative of virulent variants described in French West Indies (77). Except for CMR39, strains in Core-Rs1 were tested for pathogenicity to susceptible controls in Core-TEP under lowland (25 to $30 \pm 2{ }^{\circ} \mathrm{C}$ night and day temperature, respectively) and highlandlike (15 to $25 \pm 2{ }^{\circ} \mathrm{C}$ night and day temperature, respectively) experimental conditions. Plants were grown in climatic growth chambers (Rotoplan) with relevant levels of quarantine restrictive conditions, depending on the strains tested. Strains that had the highest aggressiveness on susceptible controls of TEP at both temperatures, as well as strains that had variable aggressiveness on TEP but belonged to other phylotypes, were selected for the next resistance tests on Core-TEP. This set of strains was encoded Core-Rs2 (Table 2). The phylogenetic position of strains in CoreRs1 was assigned after computing a phylogenetic tree (Fig. 1) based on variations in partial endoglucanase gene $(e g l)$ sequences retrieved from GenBank that included $34 \mathrm{egl}$ sequences from $R$. solanacearum Core-Rs1 strains (Table 1) and 38 additional egl sequences from $R$. solanacearum strains previously known to cover the phylogenetic diversity in this species complex. All strains in this study were deep-frozen $\left(-80^{\circ} \mathrm{C}\right)$ at CIRAD, SaintPierre, Reunion Island.

Plant material. We established the Core-TEP as an attempt to constitute a reference collection of TEP accessions representative of genetic diversity of resistance for each of these crops (Table 3). These accessions were selected from (i) literature information; (ii) passport data in Institut National de la Recherche Agronomique (INRA) genetic resource collections (information about each accession such as its name, introduction number, entry date in the collection, geographical origin, collector, and pedigree); and (iii) the expertise of H. Laterrot (INRA, France), P. Hanson (Asian
Vegetable Research Development Center [AVRDC], Taiwan), and J. Scott (University of Florida) for tomato material; M.-C. Daunay (INRA, France), P. Hanson, and J.-F. Wang (AVRDC, Taiwan) for eggplant; and A. Palloix (INRA, France) and P. Gniffke (AVRDC, Taiwan) for pepper.

For tomato, a careful analysis of the scientific literature showed that the original sources of resistance were provided for only approximately half of the breeding lines mentioned for their high resistance level. Few sources of resistance, mostly accessions of Solanum pimpinellifolium and of S. lycopersicum var. cerasiforme, are at the origin of most material resistant to bacterial wilt. Further, given the active exchange of material between breeders from the 1950s onwards, the breeding lines created at U.S. Universities (North Carolina, Hawaii, and Puerto Rico); INRA (Guadeloupe); the University of the Philippines (College of Agriculture), Los Banos; and, later, AVRDC (Taiwan), are genetically related, and their resistance partly originates from the same sources of resistance $(6,11,15,18,55)$ (Fig. 2). However, because of the complex interaction between resistance sources and strains, the use of this relatively narrow genetic basis for resistance in different environments and toward various strains suggests that a diversity of genetic resistance factors may have been bred for in the different national programs. In all, 8 of 10 tomato accessions were chosen according to their resistance to $R$. solanacearum as reported in the literature (Fig. 2). L390 was chosen as susceptible control. Finally, Okitsu Sozai no. 1 was chosen for three reasons: (i) its high level of resistance toward another bacterial and vascular disease induced by Clavibacter michiganensis subsp. michiganensis, synonym of Corynebacterium michiganense (44); (ii) its expected resistance to bacterial wilt, because this resistance is often associated with the resistance

TABLE 2. Pathogenicity of core collection of strains (Core-Rs1) of Ralstonia solanacearum to tomato, eggplant, and pepper susceptible controls ${ }^{\text {a }}$

\begin{tabular}{|c|c|c|c|c|c|c|c|c|}
\hline \multirow[b]{2}{*}{ Strain } & \multirow[b]{2}{*}{ Phylotype-sequevar } & \multirow[b]{2}{*}{ Core-Rs2 } & \multicolumn{2}{|c|}{ Tomato (L390) } & \multicolumn{2}{|c|}{ Eggplant (Florida Market) } & \multicolumn{2}{|c|}{ Pepper (Yolo Wonder) } \\
\hline & & & HT & $\mathrm{CT}$ & HT & $\mathrm{CT}$ & HT & $\mathrm{CT}$ \\
\hline GMI1000 & I-18 & $\mathrm{x}$ & +++ & ++ & +++ & +++ & +++ & +++ \\
\hline CIP365 & $\mathrm{I}-45$ & $\ldots$ & + & + & + & + & + & - \\
\hline CMR134 & $\mathrm{I}-13$ & $\mathrm{X}$ & +++ & - & +++ & +++ & +++ & +++ \\
\hline $\mathrm{R} 288$ & $\mathrm{I}-12$ & $\ldots$ & - & - & - & - & - & - \\
\hline PSS190 & $\mathrm{I}-15$ & $\ldots$ & + & - & + & - & ++ & - \\
\hline MAFF211266 & I-15 & $\ldots$ & - & - & - & - & + & - \\
\hline PSS366 & $\mathrm{I}-15$ & $\mathrm{x}$ & +++ & +++ & +++ & +++ & + & - \\
\hline PSS216 & $\mathrm{I}-13$ & $\ldots$ & ++ & ++ & ++ & +++ & ++ & - \\
\hline PSS4 & $\mathrm{I}-15$ & $\mathrm{X}$ & +++ & +++ & +++ & +++ & +++ & +++ \\
\hline UW151 & I-18 & $\ldots$ & ++ & - & ++ & ++ & + & - \\
\hline PSS358 & $\mathrm{I}-15$ & $\mathrm{x}$ & +++ & +++ & +++ & +++ & +++ & - \\
\hline IPO1609 & IIB-1 & $\ldots$ & - & - & + & + & - & - \\
\hline JT516 & IIB-1 & $\ldots$ & +++ & +++ & +++ & +++ & + & ++ \\
\hline CMR34 & IIB-1 & $\mathrm{X}$ & +++ & +++ & +++ & +++ & ++ & ++ \\
\hline CIP10 & IIB-25 & $\ldots$ & ++ & - & + & + & + & - \\
\hline NCPPB3987 & IIB-28 & $\ldots$ & + & - & + & ++ & + & + \\
\hline CFBP6784 & IIB-4NPB & $\ldots$ & +++ & +++ & ++ & ++ & ++ & ++ \\
\hline CFBP6783 & IIB-4NPB & $\mathrm{X}$ & +++ & +++ & +++ & ++ & +++ & +++ \\
\hline CIR02-080 & IIB-40 & $\ldots$ & +++ & +++ & + & ++ & +++ & +++ \\
\hline ICMP7963 & IIA-7 & $\ldots$ & + & - & + & - & + & - \\
\hline CFBP2957 & IIA-36 & $\mathrm{x}$ & +++ & ++ & ++ & ++ & +++ & + \\
\hline CIP120 & IIA-38 & $\ldots$ & + & - & + & - & + & - \\
\hline CIP239 & IIA-40 & $\ldots$ & + & - & + & - & + & - \\
\hline CMR39 & IIA-41 & $\mathrm{x}$ & ND & ND & ND & ND & ND & ND \\
\hline A3909 & IIA-6 & $\ldots$ & - & - & + & + & + & - \\
\hline B34 & IIA-24 & $\ldots$ & - & - & + & - & - & - \\
\hline JT525 & III-19 & $\ldots$ & + & + & + & + & - & + \\
\hline $\mathrm{J} 25$ & III-20 & $\ldots$ & + & - & + & + & - & - \\
\hline CFBP3059 & III-23 & $\mathrm{X}$ & +++ & +++ & ++ & +++ & +++ & ++ \\
\hline CMR15 & III-29 & $\mathrm{x}$ & +++ & +++ & +++ & +++ & + & - \\
\hline CMR32 & III-29 & $\mathrm{x}$ & + & - & + & +++ & +++ & +++ \\
\hline PSI07 & IV-10 & $\ldots$ & ++ & ++ & + & + & + & - \\
\hline MAFF301558 & IV-8 & $\ldots$ & - & - & - & - & - & - \\
\hline $\mathrm{ACH732}$ & IV-11 & $\ldots$ & + & - & - & - & - & - \\
\hline
\end{tabular}

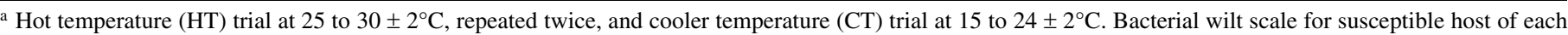
species over 10 plants for each trial: $-=$ no symptoms, $+=1$ to 4 wilted plants, $++=5$ to 8 wilted plants, and $+++=9$ to 10 wilted plants. ND $=$ not determined. 
to bacterial canker $(38,46-48)$; and (iii) because the origin of its resistance to bacterial canker originates from $L$. hirsutum var. glabratum PI 134418 (44) (i.e., from a wild source not represented in the pedigree of the other lines of Core-tomato).

For eggplant and pepper, breeding efforts have remained much more localized and pedigree information on resistant material is scarce. For accessions of both species, each distinct geographical origin can be putatively associated with a different resistance origin. The accessions were chosen within national (INRA) or international (AVRDC) germplasm collections and also within breeding material of both institutes, on the basis of their resistance in local conditions, their pedigree, or their geographic origin.

Among the nine chosen eggplant lines (Table 3), five originate from Asia (India, Sri Lanka, Indonesia, and Japan), where bacterial wilt is common. One of them, MM152 from Sri Lanka, is the source of resistance of the 1970s West Indies commercial hybrid F1 Kalenda (12). Two other lines are INRA breeding material created in Guadeloupe by G. Ano in the 1980s and accumulate resistance from different sources. The line MM931 was obtained by recurrent selection and includes in its pedigree five Asian resistant $S$. melongena lines: MM120 (China), MM165 and MM415 (Philippines), MM412 (Japan), and MM413 (from Borneo) $(2,3)$ The pedigree of the line MM960 includes one resistant $S$. melongena line, MM127 from Turkey, and the resistant $S$. aethiopicum Aculeatum group, MM134 (2,3). Finally, the two parental lines of the eggplant reference map (19), S. linnaeanum MM195 and S. melongena MM738 (a Dutch breeding line), were included in the eggplant core collection to facilitate potential mapping of resistance factors in case one of the parents carried resistance to bacterial wilt. MM136 (Florida Market) was chosen as susceptible control.

The pepper core collection was composed of nine resistant accessions belonging to three different Capsicum spp.: Capsicum

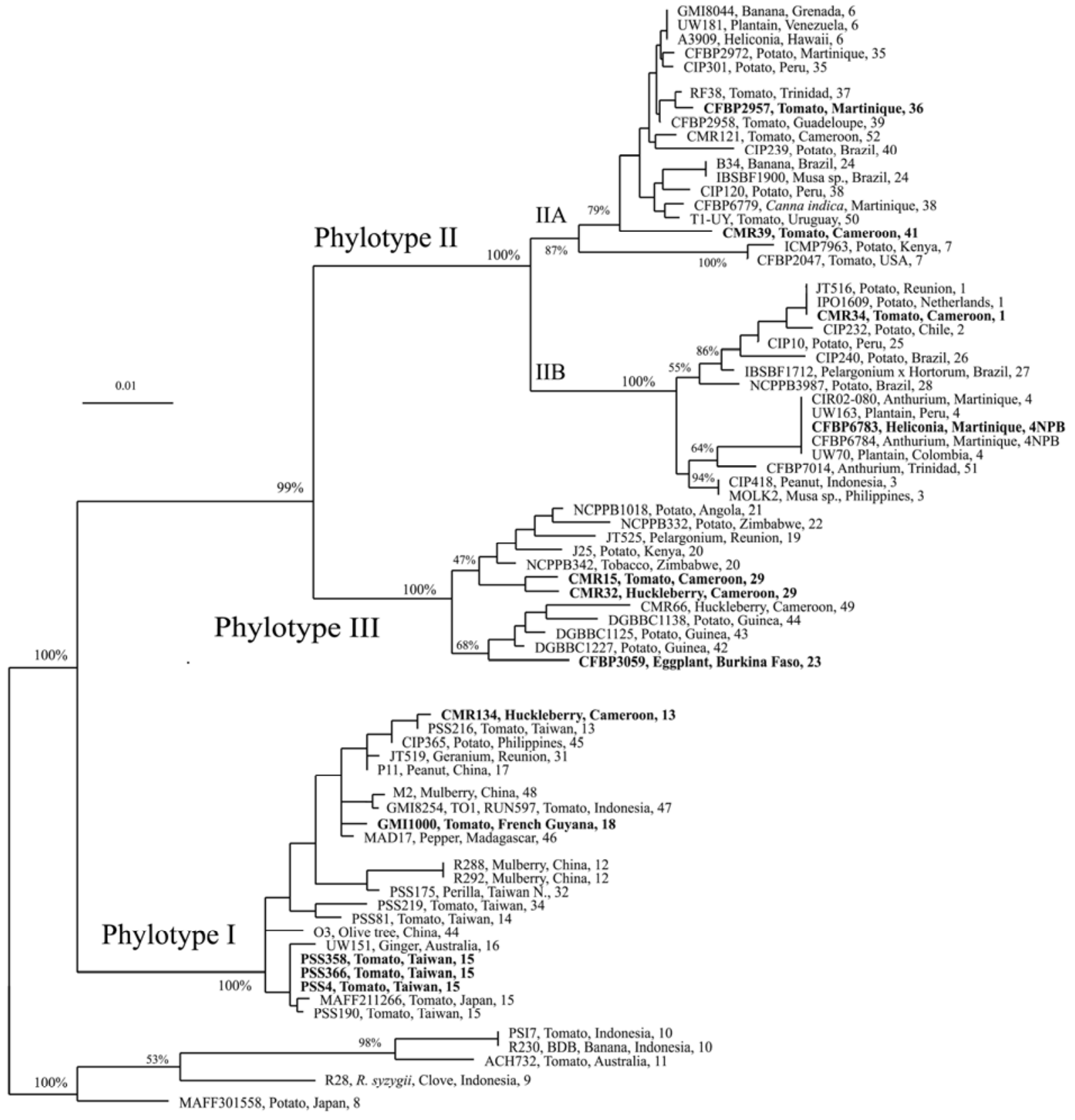

\section{Phylotype IV}

Fig. 1. Phylogenetic positions of Ralstonia solanacearum strains placed into Core-Rs1 and Core-Rs2 (bold). Neighbor-joining cladogram computed by using the Jukes-Cantor correction with 1,000 bootstrap resamplings. 
annuum, C. baccatum, and $C$. chinense. Eight of these accessions are landraces from distinct geographic origins; namely, Asia (PM659, PM687, PM1443, PBC631A, PBC66, and PBC384) and central (PM702) and South America (PM1022), and belong to different cultivar types and distinct gene pools, hence minimizing the probability of shared ancient pedigree (65). One AVRDC accession, 0209-4, originates from an interspecific cross aimed at introgressing the resistance of $C$. chinense into $C$. annuum. Three of these resistant pepper accessions (PM659, PM687, and PM702) as well as the susceptible control (Yolo Wonder) are parental lines of mapping populations (49).

Thus, the Core-TEP was composed of 24 accessions recognized as carrying genetic resistance to bacterial wilt; one tomato line resistant to bacterial canker; three lines, one per crop, used as susceptible controls; and the two parents of the eggplant reference genetic map (Table 3). Seed for Core-TEP were maintained, produced, and provided by INRA and AVRDC. For convenience, the TEP accessions were encoded as T1-T10 for tomato, E1-E10 for eggplant, and P1-P10 for pepper (Table 3).

Virulence assays. Bacterial wilt resistance was assessed in climatic growth chambers (Rotoplan) that accommodated 900 plants, with an average relative humidity of $80 \%$, a 12-h photoperiod, and 25 to $30 \pm 2{ }^{\circ} \mathrm{C}$ night and day temperatures, respectively. Strains previously assigned to a phylogenetic group present in Reunion Island were tested under routine security norm level (NS2). Strains assigned to a phylogenetic group absent from Reunion Island were considered exotic and tested under high quarantine security norm level (NS3). R. solanacearum strains were routinely grown at $30^{\circ} \mathrm{C}$ on Kelman's triphenyltetrazolium chloride (TZC) solid medium complemented with $0.5 \mathrm{~g}$ of yeast extract (41). Inoculum consisted of bacterial cells harvested from 48-h-grown culture plates by flooding with $10 \mathrm{ml}$ of Tris buffer (Sigma-Aldrich, St. Louis). The concentration of each bacterial suspension was determined by measuring the optical density
$(600 \mathrm{~nm})$ and adjusted to $10^{8} \mathrm{CFU} \mathrm{ml}{ }^{-1}$. For each test in the growth chamber, 30 plantlets of each Core-TEP accession were grown in individual pots and were infected at the stage of three to four fully expanded leaves by one Core-Rs 2 strain. Plants from each accession were isolated in a container and only one container per accession was allowed in the growth chamber. The containers were placed on a turntable that permitted homogeneous distribution of light and humidity for the plants in the growth chamber.

Disease development was visually assessed weekly, by scoring each plant as asymptomatic (no symptoms), wilted (at least one leaf wilted), or dead (all leaves wilted). Four weeks after inoculation, the asymptomatic plants were sampled and analyzed for latent infection by $R$. solanacearum. Stem sections of approximately $2 \mathrm{~cm}$ in length were sampled at the base of the stem, and then transferred to $5 \mathrm{ml}$ of Tris buffer. Stem sections were stored for 1 to $2 \mathrm{~h}$ at room temperature to allow bacteria to stream out of the xylem vessels. An aliquot $(50 \mu \mathrm{l})$ of each of these extracts was streaked onto modified Granada and Sequeira selective medium plates $(25,59)$ and incubated at $28^{\circ} \mathrm{C}$ for 3 to 4 days. Asymptomatic plants were scored positive for latent infection when characteristic colonies of $R$. solanacearum were unequivocally observed on the plates. Finally, each plant-strain combination could result in (i) a dead or wilted plant, (ii) an asymptomatic plant but hosting the bacteria in the stem (latently infected), or (iii) an asymptomatic plant not latently infected (healthy). For each Core-TEP-Core-Rs2 combination, variables describing the development of the disease were (i) percentage of final wilted plants and (ii) colonization index (CI) according the formula $C I=$ $N_{w p}+\left(N_{s} \times R_{s}\right)$, where $N_{w p}$ is the percentage of wilted plants; $N_{s}$ is the percentage of asymptomatic plants, and $R_{s}$ is the percentage of asymptomatic plants with latent infection $(26,60)$.

Statistics. Data from Core-TEP-Core-Rs2 assessment were analyzed by fuzzy analysis clustering, (fanny function) using $\mathrm{R}$

TABLE 3. Genetic resources in tomato, eggplant, and pepper that constitute the Core-TEP collection

\begin{tabular}{|c|c|c|c|c|}
\hline Code & Accession & Alternative name & Species & Seed source ${ }^{a}$ \\
\hline \multicolumn{5}{|c|}{ Tomato } \\
\hline $\mathrm{T} 1$ & CRA66 & $\ldots$ & Solanum lycopersicum var. cerasiforme & INRA \\
\hline $\mathrm{T} 2$ & Okitsu Sozai no. 1 & $\ldots$ & S. lycopersicum & INRA \\
\hline $\mathrm{T} 3$ & NC 72 TR 4-4 & $\ldots$ & S. lycopersicum & INRA \\
\hline $\mathrm{T} 4$ & IRAT L3 & $\ldots$ & S. lycopersicum & INRA \\
\hline T5 & Hawaii 7996 & $\ldots$ & S. lycopersicum & INRA \\
\hline T6 & TML46 & $\ldots$ & S. lycopersicum & AVRDC \\
\hline $\mathrm{T} 7$ & CLN1463 & $\ldots$ & S. lycopersicum & AVRDC \\
\hline $\mathrm{T} 8$ & R3034 & $\ldots$ & S. lycopersicum & AVRDC \\
\hline T9 & L285 & $\ldots$ & S. lycopersicum var. cerasiforme & AVRDC \\
\hline $\mathrm{T} 10$ & L390 & $\ldots$ & S. lycopersicum var. cerasiforme & AVRDC \\
\hline \multicolumn{5}{|c|}{ Eggplant } \\
\hline E1 & MM853 & Dingras multiple purple & S. melongena & INRA \\
\hline E2 & MM643 & SM6 & S. melongena & INRA \\
\hline E3 & MM152 & Ceylan, SM164 & S. melongena & INRA \\
\hline E4 & EG203 & Surya & S. melongena & AVRDC \\
\hline E5 & MM931 & AG91-01, RFM07-04 & S. melongena & INRA \\
\hline E6 & MM960 & AG91-25, SD20 & S. melongena & INRA \\
\hline E7 & MM195 & $\ldots$ & S. linneanum & INRA \\
\hline E8 & MM738 & $\ldots$ & S. melongena & INRA \\
\hline E9 & S56B & Terong Bulat Hijau & S. melongena & AVRDC \\
\hline E10 & MM136 & Florida Market & S. melongena & INRA \\
\hline \multicolumn{5}{|c|}{ Pepper } \\
\hline $\mathrm{P} 1$ & PM1443 & Narval & Capsicum аппиит & INRA \\
\hline $\mathrm{P} 2$ & PM687 & PI322719 & C. аппиит & INRA \\
\hline P3 & PM1022 & Cristal Blanco, Pen 79 & C. baccatum & INRA \\
\hline $\mathrm{P} 4$ & PM702 & CM334 & C. аппиит & INRA \\
\hline P5 & $0209-4$ & BC3F5 (C. annиum $\times C$. chinense $)$ & C. annuит $\times C$. chinense & AVRDC \\
\hline P6 & PBC631A & CA8 & C. аппиит & AVRDC \\
\hline P7 & PBC66 & MC4 & C. annuum & AVRDC \\
\hline P8 & PM659 & Perennial & C. annuиm & INRA \\
\hline P9 & PBC384 & $\ldots$ & C. annuum & AVRDC \\
\hline $\mathrm{P} 10$ & Yolo Wonder & $\ldots$ & C. аппиит & INRA \\
\hline
\end{tabular}

${ }^{a}$ INRA: Institut National de la Recherche Agronomique, France; AVRDC : Asian Vegetable Research Development Center, Taiwan. 
statistical freeware, version 2.7.2, and cluster package $(40,63)$. This nonhierarchical partitioning method groups the observations within a chosen number of clusters, which may overlap. Thus, by successive choice of a different number of clusters requested by the user, the method generates different typologies of clusters, illustrative of the phenotypic interactions. The method of cluster validation statistic (clusterstats function) of the $f p c$ package compares two clusterings obtained on the same dataset but differing for the number of clusters (37) in order to determine the optimal number of clusters. For this, cluster.stats function calculates the corrected Rand index (varying from 0 to 1 ). The closer the index is to 1 , the better the clustering.

For clustering the strains on the basis of their resemblance and dissimilarity for aggressiveness, the whole data set of 12 individuals (strains) and 30 variables (plant accessions) was used, with one score for each plant-strain combination calculated by

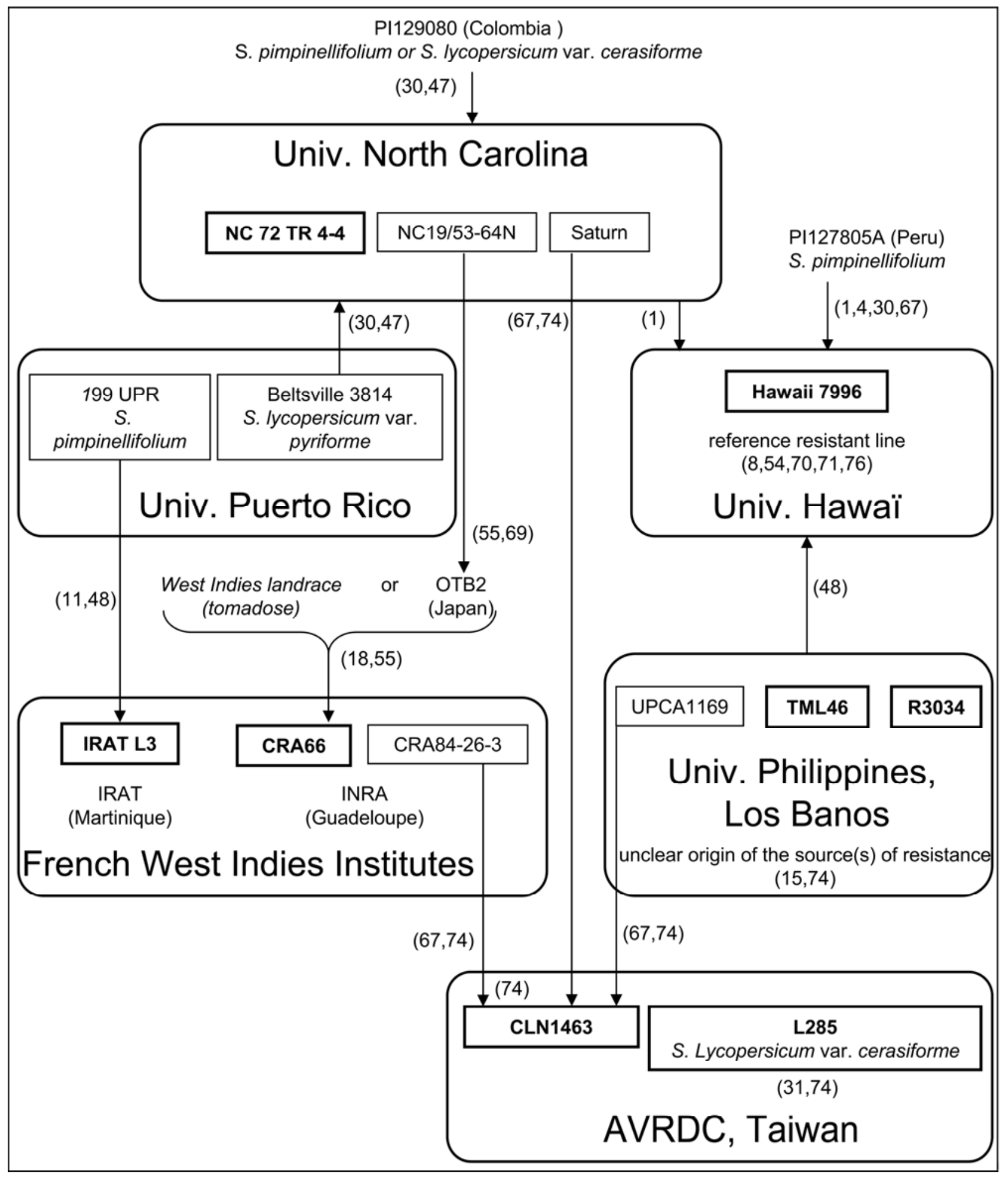

Fig. 2. Origin of and relationships between Core-Tomato accessions resistant to bacterial wilt. The Core-Tomato accessions used here are framed in bold. They are nested within the national programs from which they originated (University of North Carolina; University of Puerto Rico; University of Hawaii; French West Indies Institute; University of the Philippines; and Asian Vegetable Research Development Center, Taiwan) and which are symbolized as boxes. When known, the genitors of resistance of the Core-Tomato accessions are indicated. The figures within brackets indicate the literature references. 
fuzzy analysis. The scores were analyzed by an agglomerative hierarchical nesting classification (agnes function) which generates a dendrogram illustrating the strains' clustering. The agnes function of cluster package was used considering Euclidian distance and average linkage method (40). By observing the internode distance of the dendrogram or by using the corrected Rand index, we defined the optimal number of clusters of strains. These clusters of strains, obtained from the dataset of all accessions of Core-TEP, were called "pathoprofiles". The concept of pathoprofile is a working definition of a group of strains that presents similarities in their pattern of virulence to a given collection of solanaceous accessions; in this case, Core-TEP. On the other hand, in this study, we defined another concept, the "pathotype", as a group of strains showing a similar pattern of virulence on one species only: tomato, eggplant, or pepper. These patterns of virulence, pathotypes, were also determined by an agglomerative hierarchical nesting classification using the Euclidian distance and the average linkage method, based on the phenotypic scores obtained for each strain-plant interaction for one species.

\section{RESULTS}

Selection of strains constituting Core-Rs2. In our experimental conditions, 17 of 33 Core-Rs1 strains of $R$. solanacearum tested (Table 1) were weakly aggressive or avirulent to TEP susceptible control lines at both temperatures. These strains were phylotype I strains CIP365, R288, PSS190, and MAFF211266; phylotype IIA strain ICMP7963; potato (IPO1609, CIP10, NCPPB3987, CIP120, and CIP239), heliconia (A3909), and banana (B34) strains in phylotype IIB; strains JT525 and J25 in phylotype III; and all phylotype IV strains (PSI07, MAFF301558, and ACH732). However, PSI07 (phylotype IV) was able to cause bacterial wilt only on susceptible tomato at both temperatures. None of the phylotype IV strains were included in the Core-Rs2 because of a lack of knowledge about them and the large genetic diversity of this phylotype, which includes two different species of the $R$. solanacearum species complex, $R$. syzygii, pathogen of clove trees (Syzygium aromaticum) (61), and BDB $(20,68)$.

The remaining 17 strains were highly aggressive to most susceptible controls of TEP. Five strains with high aggressiveness toward susceptible tomato (L390), eggplant (Florida Market), and pepper (Yolo Wonder), regardless of temperature, were selected because they belong to distinct phylogenetic groups: (i) phylotype I strains GMI1000 (I/18) and PSS4 (I/15); (ii) brown rot phylotype IIB sequevar 1 strain CMR34 (IIB/1); new pathological variant phylotype IIB sequevar 4 CFBP6783 (IIB/4NPB), which is not pathogenic to banana; and (iii) phylotype III sequevar 23 strain CFBP3059 (III/23) (Table 2). For phylotype I, three additional strains were selected: CMR134 (I/13) and PSS358 (I/15), which are avirulent at cool temperature toward susceptible tomato and pepper, respectively, and strain PSS366 (I/15), which is weakly aggressive to pepper at cool and high temperature. For phylotype II, two others strains were added: CFBP2957 (IIA/36), which was very aggressive on the three solanaceous species even though it was less aggressive toward pepper at cool temperatures, and CMR39 (IIA/41), which was a unique representative of the newly described sequevar (53) even though it was not tested in the preliminary test with the susceptible solanaceous controls inoculated by Core-Rs 1 strains. For phylotype III, strains CMR15 (III/29) and CMR32 (III/29) were chosen for being weakly aggressive toward pepper and highly aggressive to tomato and eggplant, respectively, while sharing the same phylogenetic position in sequevar 29. These $12 R$. solanacearum strains constituted the Core-Rs2 (Table 2).

Typology of phenotypic interactions of Core-TEP-CoreRs2. Incidence of bacterial wilt (W) and CI for all 360 combinations between the 30 genetic resources and 12 strains of
$R$. solanacearum were analyzed (Table 4). Susceptible controls L390 (T10), Florida Market (E10), and also MM738 (E8) were susceptible to all strains placed in Core-Rs2, except for T10 (W = $23.33 \%, \mathrm{CI}=70 \%)$ and $\mathrm{E} 8(\mathrm{~W}=43.33 \%, \mathrm{CI}=43.33 \%)$, which displayed only a moderate susceptibility to the African phylotype III strain CMR32. The pepper control Yolo Wonder (P10) was not as good a susceptible control as T10, E10, or E8, because it was susceptible to only 5 of 12 strains of the Core-Rs2.

The clustering analysis of Core-TEP-Core-Rs2 interactions yielded five plant phenotypic groups: (i) highly resistant, (ii) moderately resistant, (iii) intermediate, (iv) moderately susceptible, and (v) highly susceptible (Fig. 3; Table 4). The phenotype defined as intermediate encompassed accession-strain combinations with biologically divergent scoring. Indeed, this cluster included two distinct subgroups. One was characterized by no or weak symptoms (low W score) although CI was high. For example, this subgroup included T9 $\times$ CFBP3059, with $\mathrm{W}=3 \%$ and $\mathrm{CI}=100 \%$, and $\mathrm{P} 4 \times \mathrm{CMR} 34$, with $\mathrm{W}=23.33 \%$ and $\mathrm{CI}=$ $73.33 \%$. The second was characterized by $\mathrm{W}$ and $\mathrm{CI}$ scores that differed by $<30 \%$ from each other, such as E6 $\times$ GMI1000, with $\mathrm{W}=\mathrm{CI}=43.33 \%$, or T6 $\times$ CFBP2957, with $\mathrm{W}=30 \%$ and $\mathrm{CI}=$ $46.67 \%$. These resistance phenotypes were statistically resolved by agglomerative hierarchical analysis, which clearly partitioned the combinations resulting in latent infection from those that could be considered as having partial resistance. In this way, six plant phenotypes were distinguished from the Core-TEP-CoreRs2 interactions (Fig. 3; Table 4).

Under our severe experimental conditions, none of the CoreTEP accessions was fully resistant to all Core-Rs 2 strains but a wide spectrum of high-level resistance was observed in T5, T8, E1, E2, E4, P5, P6, and P9. As expected, T2, the tomato line resistant to bacterial canker caused by Clavibacter michiganensis subsp. michiganensis, displayed resistance toward some strains of $R$. solanacearum; however, the range of this line was narrow and did not control strains virulent on the other tomato genotypes, despite the fact that its source of resistance, L. hirsutum var. glabratum, was different. Eggplant E1 displayed the broadest resistance spectrum but was susceptible to the aggressive variant CFBP6783 ( $\mathrm{W}=63.3 \%, \mathrm{CI}=63.3 \%)$. Interestingly, although CFBP6783 totally overcame bacterial wilt resistance of all tested tomato and pepper material and most eggplant accessions, the genetic resistance carried by eggplant accessions E4 (W = $26.67 \%, \mathrm{CI}=33.33 \%), \mathrm{E} 5(\mathrm{~W}=23.33 \%, \mathrm{CI}=33.33 \%)$, and, above all, $\mathrm{E} 2(\mathrm{~W}=0 \%, \mathrm{CI}=0 \%)$ was efficient in controlling this emerging strain. Most genetic resources were resistant to strains CFBP2957 and CMR32, because these strains were virulent only to T10 and E8, and E8, E10, and P2, respectively.

Pathoprofiles. Interaction scores reported for Core-TEP-CoreRs2 combinations were computed by using agglomerative hierarchical clustering. Six clusters of strains, defined on the basis of their pattern of virulence on Core-TEP, which we named "pathoprofiles," (profile) were statistically identified: (i) pathoprofile a, containing strains GMI1000 and CMR134; (ii) pathoprofile b, with only CFBP3059; (iii) pathoprofile c, with CFBP2957, CMR32, and CMR39; (iv) pathoprofile d, with PSS366 and PSS358; (v) pathoprofile e, with PSS4, CMR34, and CMR15; and (vi) pathoprofile f, with CFBP6783 (Table 4).

Pathoprofiles a and d clustered strains from phylotype I. The other strains clustered in different pathoprofiles regardless of their phylotype; for example, pathoprofiles $\mathrm{c}$ and e grouped strains of phylotypes II and III, and phylotypes I, II, and III, respectively.

The least aggressive group of strains was unified within pathoprofile c; indeed, strains CFBP2957, CMR32, and CMR39 wilted $<5$ of the 30 accessions of Core-TEP (Table 4). Pathoprofile $\mathrm{f}$ included only strain CFBP6783, an emerging pathogenic variant of Martinique, French West Indies (77), the high aggressiveness of which is demonstrated by the wilting of 26 of 30 Core-TEP accessions. Strains in pathoprofile e (PSS4, CMR34, 


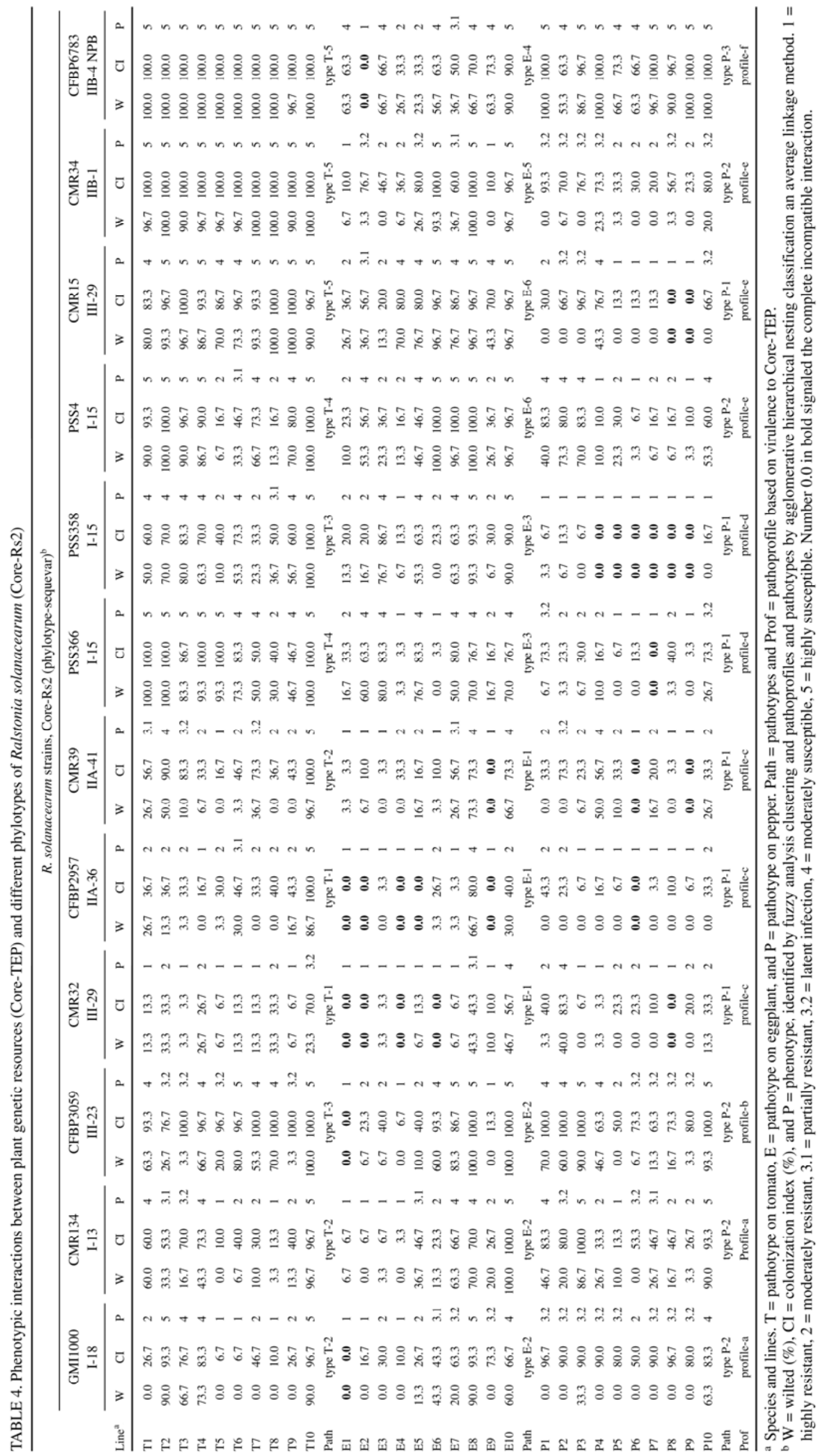


and CMR15) wilted all genetic resources tested in tomato. Pathoprofiles e and $\mathrm{f}$ are distinguished by their interaction scores for pepper, because pathoprofile $\mathrm{f}$ (CFBP6783) was highly aggressive on all pepper accessions compared with pathoprofile e. This is especially true considering the disease scores for accessions P5, P6, P7, and P9 ( $\mathrm{W}=66$ to 100 versus 0 to $3.3 \%$ and $\mathrm{CI}=63.3$ to 100 versus 0 to $56.7 \%$ ). Strains in pathoprofile a (GMI1000 and CMR134) were virulent to neither tomato T5-T9 nor eggplant E1-E4. Strains in pathoprofile d (PSS366 and PSS358) were virulent to most tomato lines, variable in aggressiveness to eggplant lines, and avirulent to most pepper accessions (no wilt and no latent infection).

Pathotypes. Additional clusterings that we named pathotypes (type) were computed according to interaction scores sorted by plant species instead of being analyzed for the whole Core-TEP, as previously.

For tomato, five pathotypes, encoded type T-1 to type T-5, were identified. Strains in type T-1 (CFBP2957 and CMR32) and type T-2 (GMI1000, CMR39, and CMR134) ranked the 10 tomato accessions the same way (T5 and T8 as the most resistant, then $\mathrm{T} 6$, and T10 and T4 as susceptible), but type T-2 was globally more aggressive than type T-1. Strains of pathotypes type T-3 (PSS358 and CFBP3059) and type T-4 (PSS366 and PSS4) were virulent on the whole tomato collection (no tomato genetic resource was highly resistant to these), and distinguished each other by their aggressiveness to T8 (tolerant or susceptible to type $\mathrm{T}-3$ and resistant to type T-4). The pathotype T-5, clustering strains CMR34, CFBP6783, and CMR15, was the most aggressive because most tomato lines were highly susceptible to this group (Table 4).

For eggplant, six pathotypes (type E-1 to type E-6) were identified, which confirmed the previous global pathoprofile clustering based on the three species, except for CMR34, which did not cluster with another strain (type E-5), and CFBP3059, which was grouped with GMI1000 and CMR134 in the pathotype type E-2 (Table 4).

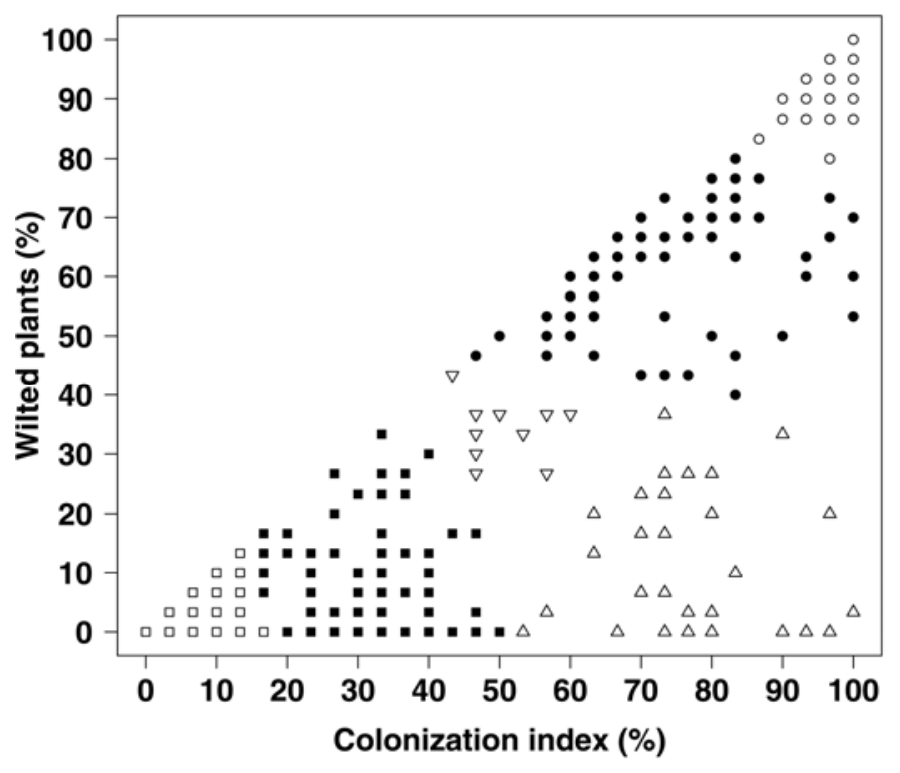

Fig. 3. Interactions observed within the collection of accessions of tomato, eggplant, and pepper (Core-TEP)-collection of pathogen strains (Core-Rs2) combinations, as defined by fuzzy analysis clustering (fanny function of package cluster under R). Bioassays were performed in growth chamber (NS2- and NS3-Rotoplan), $80 \%$ relative humidity, 25 to $30 \pm 2{ }^{\circ} \mathrm{C}$, and 12 -h photoperiod. Phenotypes were defined as highly resistant (opened squares), moderately resistant (closed squares), intermediate (triangles), susceptible (closed circles), and highly susceptible (open circles). The intermediate phenotype was partitioned into (i) partial resistant (reverse triangles) and (ii) latent infections (regular triangles).
For pepper, three pathotypes (type P-1 to type P-3) were identified. Strains in pathotype type P-2 either consistently established latent infections (GMI1000 and CMR34) or developed bacterial wilt (CMR134, CFBP3059, and PSS4) on pepper material P1, P2, P3, and P10. Strains with the least aggressiveness on pepper-namely, PSS366, PSS358, CFBP2957, CMR32, CMR39, and CMR15-were clustered in type P-1. The virulent emerging strain CFBP6783 constituted a separate cluster (type P-3) due to its high aggressiveness on all pepper accessions tested (Table 4).

\section{DISCUSSION}

To our knowledge, this is the first study investigating bacterial wilt resistance in a set of worldwide genetic resources used as sources of resistance in three solanaceous species (TEP). Resistance properties of the accessions were assessed by challenging them with strains representative of the known phylogenetic diversity of $R$. solanacearum. Thus, we tested the virulence of different strains and the response of major resistance sources. Given the origin of strains, some of these combinations may have never interacted elsewhere and will not interact until strains or resistant material disseminated.

By assessing phenotypes on the basis of percentage of wilted plants and CI, we attempted to distinguish the two mechanisms of plant defence against bacterial wilt: plant resistance based on limitation of bacterial colonization in vascular elements (true resistance) and plant resistance based on capacity to survive despite the presence of bacteria in the vessels (latent infection). The property of true resistance, previously reported by Grimault et al. (26) for tomato, accounted for a range of interactions from partially, moderately, and highly resistant to incompatible interaction $(\mathrm{W}=0 \%, \mathrm{CI}=0 \%)$. Such variation in disease severity was consistent with the complex, polygenic inheritance of resistance to bacterial wilt described in tomato $(1,13,70)$, pepper $(45)$, and, sometimes, in eggplant (14). The implications of latent infection in resistance are unclear and should be further investigated, especially in pepper. However, it is now apparent that accessions may develop no or few symptoms while being partially to highly colonized by $R$. solanacearum in the stem.

Our results showed that none of the Core-TEP accessions, representative of the TEP genetic diversity for resistance, was resistant to all Core-Rs2 strains. The absence of universal resistance is consistent with findings from Hanson et al. (30) and Wang et al. (75). Each accession displayed a specific pattern of interaction with Core-Rs2, and this strongly suggests that the mechanisms for resistance to bacterial wilt in Core-TEP differ between accessions and, thus, this specificity of resistance supports a posteriori the relevance of the choice of the accessions for constitution of the Core-TEP.

Bacterial wilt resistance (Table 4) was generally high (phenotype score encoded 1) in eggplant (36 of 120 interactions) and pepper ( 37 cases) but not in tomato (only 13 cases). These strong resistances showed a large spectrum of action in pepper and eggplant, with five and four accessions, respectively, controlling more than five strains whereas, in tomato, only one accession, Hawaii 7996 (T5), proved completely resistant to more than two strains. Moreover, for eggplant, 13 accession-strain combinations resulted in avirulence with six accessions (E1, E2, E4, E5, E6, and E9) behaving as totally resistant $(\mathrm{W}=0 \%, \mathrm{CI}=0 \%)$ toward six $R$. solanacearum strains. Incompatible interactions ( $\mathrm{W}=0 \%$, $\mathrm{CI}=0 \%)$ were also shown in pepper (P4-P9) after infection with six $R$. solanacearum strains, including PSS358 (phylotype I).

Incomplete and quantitative resistance (phenotype score encoded 2 and 3.1) was observed in all species, with 30 cases in tomato, 34 in eggplant, and 31 in pepper. This partial resistance displayed a broad spectrum of action because it was detected as a response to infection by all strains, except strains that overcame 
resistance (CFBP6783 in pepper and CFBP6783, CMR34, and CMR15 in tomato). Partial and quantitative resistance were predominant in tomato because $>58 \%$ of nonsusceptible interactions in tomato were noted as moderately (score $=2$ ) and partially ( score $=3.1$ ) resistant.

Latent infection (phenotype score encoded 3.2) was frequently observed in pepper (26 cases) as a way to resist bacterial wilt, unlike in eggplant (4 cases) and tomato (8 cases). However, in spite of high colonization by $R$. solanacearum in the stem, several pepper accessions showed no or few wilting symptoms, particularly with the strains from the type P-2 group: GMI1000 (I-1/18), CMR34 (IIB-2/1), and CMR15 (III-7/3). Thus, the ability to adapt to latent infection is not phylotype or crop specific, although it was preferentially observed in pepper, suggesting a different defence mechanism in this species. This is consistent with the results of Grimault and Prior (27), showing that the mechanisms for control of bacterial wilt in pepper may be different from those generally observed in eggplant and tomato (i.e., the restriction of bacterial colonization to the lower part of the stem and, hence, limited wilt). In contrast, tomato and eggplant wilted as soon as bacterial populations established in the plant; in other words, latent infection was not consistently observed as a defence mechanism in these hosts.

In this study, $R$. solanacearum strains exhibited specific patterns of interaction with Core-TEP accessions. Two working concepts associated with two levels of resolution of the interactions between strains and plant phenotypes were defined. One concept, the pathoprofile, is based on the interactions for the three Solanaceae spp. taken together, and the other, the pathotype, is based on the interactions for each plant species taken separately. The 12 strains of Core-Rs2 clustered into six different pathoprofiles on Core-TEP and into five pathotypes on tomato, six pathotypes on eggplant, and three pathotypes on pepper.

The pathotype of a strain provides the information needed by plant breeders and geneticists for breeding resistance in a particular crop. Although all belong to the family Solanaceae and are genetically related, tomato, eggplant, and pepper interacted differently with the strains of Core-Rs2, as reflected by the different number of pathotypes for each species. This was also reported by AVRDC studies on aggressiveness of $R$. solanacearum strains to tomato and pepper species, which described five pathotypes in tomato (72) and four pathotypes in pepper (73). The number of pathotypes that can be defined on each crop species is, of course, dependent on the $R$. solanacearum strains used, the degree to which they represent the bacterium's genetic diversity, the solanaceous accessions used, and the variables used for describing the disease.

In our study, pathotypes ranked from least (type 1) to most aggressive to tomato (type T-5) and pepper (type P-3). The virulence tests on tomato and pepper clustered the accessions into two groups: resistant accessions (T5-T9 and P5-P9) and susceptible accessions (T1-T4 and T10 and P1-P4 and P10) (data not shown). The situation differed in eggplant because virulence traits of strains in pathotype E could not be clearly ranked and, conversely, the eggplant accessions did not cluster in response to a global phenotype of strains. Knowledge of pathotype identity of the pathogen population present in a particular cultivation area will be helpful for (i) deploying cultivars possessing the relevant resistance background and (ii) improving breeding strategies for creating new material recombining the appropriate resistance factors.

Strain pathoprofile is a working definition to conceptualize the way a similar virulence pattern carried by different strains of $R$. solanacearum may mirror their coevolution with solanaceous crops that share intergenomic synteny $(19,78,79)$. The pathoprofile concept provides general information on the virulence traits shared by strains differing in their phylogenetic and phylogeographic background. This information may be of great value to plant breeders working on global improvement of bac- terial wilt resistance of TEP as well as to plant geneticists who are unravelling the underlying resistance mechanisms. Currently, Core-TEP is being field tested in different geographical locations as a validation of the predictability of the local $R$. solanacearum population pathoprofile.

The concepts of pathoprofiles and pathotypes described in this study, together with recent results on bacterial gene content (coreand variable-genome) as revealed by pangenomic comparative hybridization (29), and biological mining of available genomes of the $R$. solanacearum species complex $(28,64,66)$ should further our understanding of bacterial speciation. In addition, incompatible interaction and latent infection may be good models to be used in comparative genomics for identifying bacterial gene repertoires associated with these phenotypes. Our results and the new concepts proposed here should be invaluable tools for suggesting new research directions for mapping the plant genetic factors involved in resistance to bacterial wilt, especially in eggplant and pepper. For mapping resistance factors, the phenotypes of the parents of the mapping population must be as phenotypically different as possible.

Interestingly, strains in Core-Rs 2 distributed, independently of phylotypes, into pathoprofiles and into pathotypes on TEP, except for pathoprofiles a and d and pathotypes type T-4 and type E-3. Hence, virulence patterns are generally not phylotype specific, although phylotype-specific resistance QTLs were identified by Carmeille et al. (8) on the basis of two strains belonging to two phylotypes. Phylotype classification is indicative of the evolutionary past of the organism $(9,10,22)$ because it was established from sequence variations observed in different housekeeping genes. Thus, it is not surprising that phylotypes do not relate to pathogenicity and virulence. In fact, this has already been reported for a population of $R$. solanacearum collected from tomato production fields in Taiwan (39). Consequently, our pathoprofiles emerge from different phylogenic lineages of the $R$. solanacearum species complex. Meanwhile, strains assigned to phylotypes I, III, and IIB also assigned to pathoprofiles $\mathrm{d}$, e, and $\mathrm{f}$ and to pathotypes type T-5, type E-6, and type P-3, respectively, with high virulence patterns.

Extreme aggressiveness was demonstrated for strain CFBP6783, a representative of a virulent variant emerging in Martinique (77), because this strain overcame resistance of 26 of 30 genetic resources tested. No resistance carried by tomato or pepper accessions was effective for controlling it; however, resistance was found in four eggplant accessions. This strain lineage is also highly aggressive to Anthurium, Heliconiaceae, and Cucurbitaceae and is reported to cause heavy damage to solanaceous crops (77). We identified one eggplant accession that was highly resistant to this strain, MM643 (E2), originating from India. The reason why resistance was found in an Indian accession remains unexplained.

Virulence assays in this study deciphered plant-bacteria interactions that resulted from infection with high inoculum pressure and plant growth in an artificially controlled environment. In these experimental conditions, we determined that absence of symptoms can result from either true resistance or tolerance to $R$. solanacearum, depending on the accession-strain combination. This set of unique data should be considered as a starting point from which clear-cut scientific models for studying compatible and incompatible interactions in this pathosystem may be easily extended. In the era of biological mining, genomics, and post genomics, such models will allow straightforward investigation of what makes $R$. solanacearum so difficult to control on a long-term basis.

\section{ACKNOWLEDGMENTS}

We thank the Institut National de la Recherche Agronomique (INRA) and the Asian Vegetable Research Development Center (AVRDC)-The 
World Vegetable Center for sharing and multiplying plant materials used in this study; J. M. Baptiste, J. J. Cheron, and S. Lebon for providing technical assistance; S. Jégo for providing statistical assistance; and De Ruiter Seeds, Enza Zaden, Gautier Semences, Nunhems, Rijk Zwaan, and Vilmorin for financial support for this work. The European Regional Development Funds (ERDF) of the European Union, Conseil Regional de la Réunion also provided financial support as part of Gentom programme.

\section{LITERATURE CITED}

1. Acosta, J., Gilbert, J., and Quinon, V. 1964. Heritability of bacterial wilt resistance in tomato. Proc. Am. Soc. Hortic. Sci. 84:455-461.

2. Ano, G., Hébert, Y., Prior, P., and Messiaen, C. M. 1991. A new source of resistance to bacterial wilt of eggplants obtained from a cross: Solanum aethiopicum L. x Solanum melongena L. Agronomie 11:555-560.

3. Ano, G., Prior, P., Manyri, J., and Vincent, C. 1990. Stratégies d'amélioration de l'aubergine (Solanum melongena L.) pour la résistance au flétrissement bactérien causé par Pseudomonas solanacearum E.F.S. Journ. Maraîchères CIRAD-ORSTOM-INRA:570-579.

4. Balatero, C. H., and Hautea, D. M. 2001. Identification of AFLP and RGA markers associated with bacterial wilt resistance QTL derived from tomato Lycopersicon pimpinellifolium. Pages 225-243 in: Solanaceae V: Advances in Taxonomy and Utilization. R. G. van den Berg, G. W. M. Barendse, G. M. van der Weerden, and C. Mariani, eds. Nijmegen University Press.

5. Balatero, C. H., Hautea, D. M., Narciso, J. O., and Hanson, P. M. 2005. QTL mapping for bacterial wilt resistance in Hawaii 7996 using AFLP, RGA, and SSR markers. Pages 301-307 in: Bacterial Wilt Disease and the Ralstonia solanacearum Species Complex. C. Allen, P. Prior, and A. C. Hayward, eds. American Phytopathological Society Press, St. Paul, MN.

6. Buddenhagen, I., and Kelman, A. 1964. Biological and physiological aspects of bacterial wilt caused by Pseudomonas solanacearum. Annu. Rev. Phytopathol. 2:203-230.

7. Buddenhagen, I., Sequeira, L., and Kelman, A. 1962. Designation of races in Pseudomonas solanacearum. (Abstr.) Phytopathology 52:726.

8. Carmeille, A., Caranta, C., Dintinger, J., Prior, P., Luisetti, J., and Besse, P. 2006. Identification of QTLs for Ralstonia solanacearum race 3phylotype II resistance in tomato. Theor. Appl. Genet. 113:110-121.

9. Cook, D., Barlow, E., and Sequeira, L. 1989. Genetic diversity of Pseudomonas solanacearum: detection of restriction fragment polymorphisms with DNA probes that specify virulence and hypersensitive response. Mol. Plant-Microbe Interact. 2:113-121.

10. Cook, D., and Sequeira, L. 1994. Strain differentiation of Pseudomonas solanacearum by molecular genetic methods. Pages 77-93 in: Bacterial Wilt: The Disease and Its Causative Agent, Pseudomonas solanacearum. A. C. Hayward and G. L. Hartman, eds. CAB International, Wallingford, UK.

11. Daly, P. 1976. "IRAT L3" une nouvelle variété de tomate combinant plusieurs résistance aux maladies. Agron. Trop. 31:398-402.

12. Daly, P. 1986. L'implantation de l'aubergine aux Antilles ou la nécessaire adaptation du matériel végétal à des problèmes sanitaires. Bull. Tech. Inf. 409/411:453-457.

13. Danesh, D., Aarons, S., Mcgill, G. E., and Young, N. D. 1994. Genetic dissection of oligogenic resistance to bacterial wilt in tomato. Mol. PlantMicrobe Interact. 7:464-471.

14. Daunay, M. C. 2008. Eggplant. Pages 163-220 in: Vegetables II: Fabaceae, Liliaceae, Solanaceae, and Umbelliferae. J. Prohens and F. Nuez, eds. Springer, New York.

15. Deanon, J. R., Jr. 1988. Biochemical bases of screening tomato for bacterial wilt resistance. Pages 83-99 in: Current Problems on Fruits and Vegetables. Philippines Council for Agriculture Forestry and Natural Resources Research and Development, Los Banos, Laguna, Philippines.

16. Deberdt, P., Quénéhervé, P., Darrasse, A., and Prior, P. 1999. Increased susceptibility to bacterial wilt in tomatoes by nematode galling and the role of the $M i$ gene in resistance to nematodes and bacterial wilt. Plant Pathol. 48:408-414.

17. Denny, T. 2006. Plant pathogenic Ralstonia species. Pages 573-644 in: Plant-Associated Bacteria. S. S. Gnanamanickam, ed. Springer, Dordrecht, The Netherlands.

18. Digat, B., and M., Derieux. 1968. A study of the varietal resistance to bacterial wilt. Pages 95-101 in: Proc. Caribbean Food Crops Soc. 6th Annu. Meet. St. Augustine, Trinidad.

19. Doganlar, S., Frary, A., Daunay, M. C., Lester, R. N., and Tanksley, S. 2002. A comparative genetic linkage map of eggplant (Solanum melongena) and its implications for genome evolution in the Solanaceae. Genetics 161:1697-1711.

20. Eden-Green, S. J. 1994. Diversity of Pseudomonas solanacearum and related bacteria in South East Asia: New direction for moko disease. Pages 25-34 in: Bacterial Wilt: The Disease and Its Causative Organism, Pseudomonas solanacearum. A. C. Hayward and G. L. Hartman, eds.
CAB International, Wallingford, UK.

21. Elphinstone, J. G. 2005. The current bacterial wilt situation: a global overview. Pages 9-28 in: Bacterial Wilt Disease and the Ralstonia solanacearum Species Complex. C. Allen, P. Prior, and A. C. Hayward, eds. American Phytopathological Society Press, St. Paul, MN.

22. Fegan, M., and Prior, P. 2005. How complex is the "Ralstonia solanacearum species complex". Pages 449-461 in: Bacterial Wilt Disease and the Ralstonia solanacearum Species Complex. C. Allen, P. Prior, and A. C. Hayward. American Phytopathological Society Press, St. Paul, MN.

23. Fegan, M., and Prior, P. 2006. Diverse members of the Ralstonia solanacearum species complex cause bacterial wilts of banana. Australas. Plant Pathol. 35:93-101.

24. Gillings, M. R., and Fahy, P. 1994. Genomic fingerprinting: towards a unified view of the Pseudomonas solanacarum species complex. Pages 95-112 in: Bacterial Wilt: The Disease and Its Causative Agent, Pseudomonas solanacearum. A. C. Hayward and G. L. Hartman, eds. $\mathrm{CAB}$ International, Wallingford, UK.

25. Granada, G., and Sequeira, L. 1983. A new selective medium for Pseudomonas solanacearum. Plant Dis. 67:1084-1088.

26. Grimault, V., Anais, G., and Prior, P. 1994. Distribution of Pseudomonas solanacearum in the stem tissues of tomato plants with different levels of resistance to bacterial wilt. Plant Pathol. 43:663-668.

27. Grimault, V., and Prior, P. 1994. Invasiveness of Pseudomonas solanacearum in tomato, eggplant and pepper: a comparative study. Eur. J. Plant Pathol. 100:259-267.

28. Guidot, A., Elbaz, M., Carrère, S., Siri, M. I., Pianzzola, M. J., Prior, P., and Boucher, C. 2009. Specific genes from the potato brown rot strains of Ralstonia solanacearum and their potential use for strain detection. Phytopathology 99:1105-1112.

29. Guidot, A., Prior, P., Schoenfeld, J., Carrere, S., Genin, S., and Boucher, C. 2007. Genomic structure and phylogeny of the plant pathogen Ralstonia solanacearum inferred from gene distribution analysis. J. Bacteriol. 189:377-387.

30. Hanson, P. M., Licardo, O., Hanudin, Wang, J. F., and Chen, J. T. 1998. Diallel analysis of bacterial wilt resistance in tomato derived from different sources. Plant Dis. 82:74-78.

31. Hanson, P. M., Wang, J. F., Licardo, O., Hanudin, Mah, S. Y., Hartman, G. L., Lin, Y. C., and Chen, J. T. 1996. Variable reactions of tomato lines to bacterial wilt evaluated at several locations in Southeast Asia. HortScience 31:143-146.

32. Hanudin, and Hanafiah Gaos, M. A. 1993. Screening of eggplant accessions for resistance to bacterial wilt. Pages 191-192 in: Bacterial Wilt. ACIAR Proc. No. 45. G. L. Hartman and A. C. Hayward, eds. ACIAR, Canberra, Australia.

33. Hayward, A. C. 1964. Characteristics of Pseudomonas solanacearum. J. Appl. Bacteriol. 27:265-277.

34. Hayward, A. C. 1991. Biology and epidemiology of bacterial wilt caused by Pseudomonas solanacearum. Annu. Rev. Phytopathol. 29:67-87.

35. Hayward, A. C. 1994. The hosts of Pseudomonas solanacearum. Pages 924 in Bacterial Wilt: The Disease and Its Causative Agent, Pseudomonas solanacearum. A. C. Hayward and G. L. Hartman, eds. CAB International, Wallingford, UK.

36. He, L. Y., Sequeira, L., and Kelman, A. 1983. Characteristics of strains of Pseudomonas solanacearum from China. Plant Dis. 67:1357-1361.

37. Hennig, C. 2007. fpc: Fixed point clusters, clusterwise regression and discriminant plots. $\mathrm{R}$ package, version 1.2-3. http://www.homepages.ucl.ac.uk/ ucakche.

38. Jahr, H., Dreier, J., Meletzus, D., Bahro, R., and Eichenlaub, R. 2000. The endo- $\beta-1,4$-glucanase CelA of Clavibacter michiganensis subsp. michiganensis is a pathogenicity determinant required for induction of bacterial wilt of tomato. Mol. Plant-Microbe Interact. 13:703-714.

39. Jaunet, T. X., and Wang, J. F. 1999. Variation in genotype and aggressiveness of Ralstonia solanacearum race 1 isolated from tomato in Taiwan. Phytopathology 89:320-327.

40. Kaufman, L, and Rousseeuw, P. J., eds. 1990. Finding Groups in Data: An Introduction to Cluster Analysis. Wiley, New York.

41. Kelman, A. 1954. The relationship of pathogenicity in Pseudomonas solanacearum to colony appearance on a tetrazolium medium. Phytopathology 44:693-695.

42. Kelman, A. 1998. One hundred and one years of research on bacterial wilt. Pages 1-5 in: Bacterial Wilt Disease: Molecular and Ecological Aspects. P. Prior, C. Allen, and J. Elphinstone, eds. Springer.

43. Krausz, J. P., and Thurston, H. D. 1975. Breakdown of resistance to Pseudomonas solanacearum in tomato. Phytopathology 65:1272-1274.

44. Kuriyama, T., and Kuniyasu, K. 1974. Studies on the breeding of disease resistant tomato by interspecific hybridization. III. On the breeding of a new tomato line resistant to bacterial canker caused by Corynebacterium michiganense. Bull. Veg. Ornamental Crops Res. Stn. Ser. A I:93-107.

45. Lafortune, D., Béramis, M., Daubèze, A.-M., Boissot, N., and Palloix, A. 2005. Partial resistance of pepper to bacterial wilt is oligonenic and stable 
under tropical conditions. Plant Dis. 89:501-506.

46. Laterrot, H. 1999. Resistance to bacteria in tomato. Pages 103-110 in: Genetics and Breeding for Crop Quality and Resistance. G. T. Scarascia Mugnozza, E. Porceddu, and M. A. Pagnotta. Kluwer Academic Publishers, Dordrecht, The Netherlands.

47. Laterrot, H., Brand, R., and Daunay, M. C. 1978. La résistance à Corynebacterium michiganense chez la tomate. Ann. Amelior. Plant. 28:579-591.

48. Laterrot, H., and Kaan, F. 1978. Resistance to Corynebacterium michiganense of lines bred for resistance to Pseudomonas solanacearum. Rep. Tomato Genet. Coop. 28.

49. Lefebvre, V., Pflieger, S., Thabuis, A., Caranta, C., Blattes, A., Chauvet, J. C., Daubeze, A. M., and Palloix, A. 2002. Towards the saturation of the pepper linkage map by alignement of three intraspecific maps including known-function genes. Genome 45:839-854.

50. Li, H. P., Goth, R. W., and Barksdale, T. H. 1988. Evaluation of resistance to bacterial wilt in eggplant. Plant Dis. 72:437-439.

51. Lopes, C. A., and Boiteux, L. S. 2004. Biovar-specific and broadspectrum sources of resistance to bacterial wilt (Ralstonia solanacearum) in Capsicum. Crop Breed. Appl. Biotechnol. (Brazil) 4:350-355.

52. Lopes, C. A., Carvalho, S. I. C., and Boiteux, L. S. 2006. Prevalence of biovar 3 on bell peppers in Brazil and identification of biovar-specific response to Ralstonia solanacearum in Capsicum germplasm. Paper read at 4th Int. Bacterial Wilt Symp. York, UK.

53. Mahbou Somo Toukam, G., Cellier, G., Wicker, E., Guilbaud, C., Kahane, R., Allen, C., and Prior, P. 2009. Broad Diversity of Ralstonia solanacearum strains in Cameroon. Plant Dis. 93:1123-1130.

54. Mangin, B., Thoquet, P., Olivier, J., and Grimsley, N. H. 1999. Temporal and multiple quantitative trait loci analyses of resistance to bacterial wilt in tomato permit the resolution of linked loci. Genetics 151:1165-1172.

55. Messiaen, C. M., Laterrot, H., and Kaan, F. 1978. Cumulate resistances to Pseudomonas solanacearum and to Meloidogyne icognita with determinate growth in tomato. Pages 48-51 in: Vegetables for the Hot Humid Rropics. Mayaguez Institute of Tropical Agriculture, Puerto Rico.

56. Pegg, K. G., and Moffett, M. 1971. Host range of the ginger strain of Pseudomonas solanacearum in Queensland. Aust. J. Exp. Agric. Anim. Husb. 11:696-698.

57. Peter, K. V., Gopalakrishnan, T. R., Rajan, S., and Sadhan Kumar, P. G. 1993. Breeding for resistance to bacterial wilt in tomato, eggplant and pepper. Pages 183-190 in: Bacterial Wilt. ACIAR Proc. No. 45. G. L. Hartman and A. C. Hayward, eds. ACIAR, Canberra, Australia.

58. Poussier, S., Prior, P., Luisetti, J., Hayward, C., and Fegan, M. 2000. Partial sequencing of the $h r p B$ and endoglucanase genes confirms and expands the known diversity within the Ralstonia solanacearum species complex. Syst. Appl.Microbiol. 23:479-486.

59. Poussier, S., Vandewalle, P., and Luisetti, J. 1999. Genetic diversity of African and worldwide strains of Ralstonia solanacearum as determined by PCR-restriction fragment length polymorphism analysis of the hrp gene region. Appl. Environ. Microbiol. 65:2184-2194.

60. Prior, P., Bart, S., Leclercq, S., Darrasse, A., and Anais, G. 1996. Resistance to bacterial wilt in tomato as discerned by spread of Pseudomonas (Burholderia) solanacearum in the stem tissues. Plant Pathol. 45:720-726.

61. Prior, P., and Fegan, M. 2005. Recent developments in the phylogeny and classification of Ralstonia solanacearum. Pages 127-136 in: Proc. First Int. Symp. Tomato Dis. M. T. Momol, P. Ji, and J. B. Jones, eds. Acta Horticulturae, Orlando, FL.

62. Rahman, M. A., Abullah, H., and Vanhaecke, M. 1999. Histopathology of susceptible and resistant Capsicum annuum cultivars infected with Ralstonia solanacearum. J. Phytopathol. 147:129-140.

63. R Development Core Team. 2008. R: a language and environment for statistical computing. R Foundation for Statistical Computing, Vienna

64. Remenant, B., Coupat-Goutaland, B., Guidot, A., Cellier, G., Wicker, E., Allen, C., Fegan, M., Pruvost, O., Elbaz, M., Calteau, A., Salvignol, G., Mornico, D., Mangenot, S., Barbe, V., Medigue, C., and Prior, P. 2010. Genomes of three tomato pathogens within the Ralstonia solanacearum species complex reveal significant evolutionary divergence. BMC Genomics 11:379.
65. Sage-Palloix, A. M., Jourdan, F., Phaly, T., Nemouchi, G., Lefebvre, V., and Palloix, A. 2007. Structuring genetic diversity in pepper genetic resources: distribution of horticultural and resistance traits in the INRA pepper germplasm. Pages 33-42 in: Progress in Research on Capsicum and Eggplant. K. Niemirowicz-Szczytt, ed. Warsaw University of Life Sciences Press, Warsaw.

66. Salanoubat, M., Genin, S., Artiguenave, F., Gouzy, J., Mangenot, S., Arlat, M., Billault, A., Brottier, P., Camus, J. C., Cattolico, L., Chandler, M., Choisne, N., Claudel-Renard, C., Cunnac, S., Demange, N., Gaspin, C., Lavie, M., Moisan, A., Robert, C., Saurin, W., Schiex, T., Siguier, P., Thebault, P., Whalen, M., Wincker, P., Levy, M., Weissenbach, J., and Boucher, C. A. 2002. Genome sequence of the plant pathogen Ralstonia solanacearum. Nature 415:497-502.

67. Scott, J. W., Wang, J. F., and Hanson, P. M. 2005. Breeding tomatoes for resistance to bacterial wilt, a global view. Pages 161-172 in: Proc. First Int. Symp. Tomato Dis. M. T. Momol, P. Ji, and J. B. Jones, eds. International Society Horticultural Science, Brugge, Belgium.

68. Seal, S. E., Jackson, L. A., Young, J. P. W., and Daniels, M. J. 1993. Differentiation of Pseudomonas solanacearum, Pseudomonas syzygii, Pseudomonas pickettii and the blood disease bacterium by partial $16 \mathrm{~S}$ rRNA sequencing: construction of oligonucleotide primers for sensitive detection by polymerase chain reaction. J. Gen. Microbiol. 139:15871594.

69. Suzuki, I., Sugahara, Y., Kotani, A., Todaka, S., and Shimada, H. 1964. Studies on breeding eggplants and tomatoes for resistance to bacterial wilt. I. Investigations on method of evaluating the resistance and on the source of resistance in eggplants and tomatoes. Bull. Hortic. Res. Stn. Ser. A 3:77-106.

70. Thoquet, P., Olivier, J., Sperisen, C., Rogowsky, P., Laterrot, H., and Grimsley, N. 1996. Quantitative trait loci determining resistance to bacterial wilt in tomato cultivar Hawaii7996. Mol. Plant-Microbe Interact. 9:826-836.

71. Thoquet, P., Oliver, J., Sperisen, C., Rogowsky, P., Prior, P., Anaïs, G., Mangin, B., Bazin, B., Nazer, R., and Grimsley, N. 1996. Polygenic resistance of tomato plants to bacterial wilt in the French West Indies. Mol. Plant-Microbe Interact. 9:837-842.

72. Wang, J. F. 2001. Variation of Ralstonia solanacearum strains isolated from tomato plants in Indonesia, Philippines, and Taiwan. In: AVRDC Report 2000. Asian Vegetable Research and Development Center, Shanhua, Taiwan.

73. Wang, J. F. 2004. Characterization of Ralstonia solanacearum strains isolated from pepper in Taiwan. In: AVRDC Report 2003. AVRDC-The World Vegetable Center, Shanhua, Taiwan.

74. Wang, J. F., Chen, J. T., and Li, H. M. 1998. Resistance sources to bacterial wilt in eggplant (Solanum melongena). Pages 284-289 in: Bacterial Wilt Disease-Molecular and Ecological Aspects. P. Prior, C. Allen, and J. G. Elphinstone, eds. Springer-Verlag, Berlin.

75. Wang, J. F., Hanson, P., and Barnes, J. A. 1998. Worlwide evaluation of an international set of resistant sources to bacterial wilt in tomato. Pages 269-275 in: Bacterial Wilt Disease-Molecular and Ecological Aspects. P. Prior, C. Allen, and J. G. Elphinstone, eds. Springer-Verlag, Berlin.

76. Wang, J. F., Olivier, J., Thoquet, P., Mangin, B., Sauviac, L., and Grimsley, N. H. 2000. Resistance of tomato line Hawaii7996 to Ralstonia solanacearum Pss 4 in Taiwan is controlled mainly by a major strainspecific locus. Mol. Plant-Microbe Interact. 13:6-13.

77. Wicker, E., Grassart, L., Coranson-Beaudu, R., Mian, D., Guilbaud, C., Fegan, M., and Prior, P. 2007. Ralstonia solanacearum strains from Martinique (French West Indies) exhibiting a new pathogenic potential. Appl. Environ. Microbiol. 73:6790-6801.

78. Wu, F., Eannetta, N. T., Xu, Y., Durrett, R., Mazourek, M., Jahn, M. M., and Tanksley, S. D. 2009. A COSII genetic map of the pepper genome provides a detailled picture of synteny with tomato and new insights into recent chromosome evolution in the genus Capsicum. Theor. Appl. Genet. 118:1279-1293

79. Wu, F. N., Eannetta, N. T., Xu, Y. M., and Tanksley, S. D. 2009. A detailed synteny map of the eggplant genome based on conserved ortholog set II (COSII) markers. Theor. Appl. Genet. 118:927-935. 